\title{
Reviving community medicine in India: The need to perform our primary role
}

Hemant Deepak Shewade, Kathiresan Jeyashree', Palanivel Chinnakali

Department of Community Medicine, Indira Gandhi Medical College and Research Institute (a Government of Puducherry Institute), Puducherry, ${ }^{1}$ School of Public Health,

Post Graduate Institute of Medical Education and Research, Chandigarh, India

Address for the Correspondence:

Dr. Hemant Deepak Shewade, Assistant Professor of Community

Medicine, Indira Gandhi Medical College and Research Institute (a Government of Puducherry Institute), Puducherry - 605009 ,

India.

E-mail: hemantjipmer@gmail.com

\begin{tabular}{|l|}
\hline Access this article online \\
\hline Website: www.ijmedph.org \\
\hline DOI: 10.4103/2230-8598.127119 \\
\hline Quick response code: \\
\hline
\end{tabular}

Community medicine broadly comprises of family medicine and public health; and community physicians are those trained in both. The primary professional role of a community physician is to manage a health center. Provision of primary healthcare: Curative, preventive, and promotive are an integral part of community medicine practice. Despite being a clinical specialty, community physicians in India are not performing this role and Rural and Urban Health Training Centers have become ornamental exhibits. Most departments of community medicine have restricted themselves to teaching undergraduates and postgraduate training has taken a back seat. Instead of pondering upon why this cadre of social/community physicians was prepared, we are hastily opening up other public health courses. Clinical subspecialties of community medicine should be given equal importance at par with academics and research. Community physicians should fulfill their primary role which would enable them to advocate public health policy with authority.

Key words: Community medicine, community physician, family medicine, professional role, primary healthcare, public health

\section{INTRODUCTION}

Community medicine is known by various other names viz. community health, public health, preventive and social medicine, etc., and each term having its own origin. In the $19^{\text {th }}$ century, Modern Public Health started as an offshoot of the works of $\mathrm{E}$ Chadwick on environmental and sanitation conditions in London. It dealt with water, hygiene, sanitation, and other environmental issues which affected health. Preventive medicine took off with the advent of antimicrobials and vaccines. Social medicine had its origins in Europe which dealt with social determinants of health. The concept of community medicine started in South Africa in 1940s when the need was felt to incorporate family medicine into preventive and social medicine to deliver primary healthcare. ${ }^{[1]}$ Thus, primary healthcare provision became a part and parcel of our specialty. With the emergence of noncommunicable diseases, some of them with a microbial etiology, there was an overlap in the roles of both public health and preventive and social medicine. In the UK, community medicine specialists were also given the role of management of health services/programs. ${ }^{[2]}$ They were called as practitioners of public health medicine.

Origin of community medicine in India can be traced back to 1946. Health Survey and Development Committee (Bhore) Report recommended a 3 month compulsory training for physicians in preventive and social medicine. ${ }^{[3]}$ Focus then was to impart preventive as well as curative service training to the physicians. Community medicine departments have ever since played an important role in imparting public health education at undergraduate and postgraduate level..$^{[4,5]}$ The term community medicine is preferred and most of the new departments in medical colleges of India are Christened departments of community medicine.

Family Medicine, epidemiology, health management, and health promotion are the major concentrations in community medicine with an inkling of social sciences, health economics, and environmental and occupational health. ${ }^{[6]}$ There are clinical subspecialties of community medicine like community ophthalmology, preventive oncology, preventive cardiology, social/community pediatrics, social/ community obstetrics, human nutrition, and family medicine. There are also nonclinical subspecialties namely health management, health promotion, epidemiology, research methodology, medical biostatistics, health economics, and behavioral sciences. ${ }^{[7]}$ 
As shall now be evident from the background, community medicine broadly comprises of family medicine and public health and community physicians are those trained in both. While family medicine deals with delivering preventive and curative primary healthcare to a specified population, public health deals with disease prevention and health promotion by working at policy level. ${ }^{[8]}$ Community physicians on a larger scale may be called public health practitioners. We shall be using the term community physicians, henceforth in the manuscript, to refer to these public health practitioners for the ease of understanding.

\section{PRIMARY PROFESSIONAL ROLE OF A COMMUNITY PHYSICIAN}

A community physician manages a health center (Primary/ Community Health Center (CHC)/District Hospitals), one that provides comprehensive healthcare at various levels. In addition to providing primary healthcare (outpatient department (OPD) and emergency), $s /$ he is also in charge of health management, health program implementation, health promotion, health information system and healthcare facilities at primary and secondary level. These health centers in medical colleges are generally called Urban Health and Training Centers and Rural Health and Training Centers (UHTC/RHTC). These are used to develop a model healthcare delivery system addressing biological and social determinants of health which may be replicated in other primary healthcare centers (PHCs) as well. It is here that the doctors (undergraduates and postgraduates) shall be trained in primary healthcare, as conceived by the Bhore committee.

\section{OTHER ROLES OF A COMMUNITY PHYSICIAN}

In addition to the primary role, a community physician should also be involved in the following:

\section{Postgraduate training}

Community physicians train postgraduates (PGs) of their own specialty and others, in community oriented care. The PGs work under the guidance of the community physician (faculty of community medicine) in the RHTC/UHTC to provide communitybased curative, preventive, and promotive care. During this process $\mathrm{s} /$ he attains various skills under each of the community medicine subspecialties. Training the postgraduates of other specialties will expose them to primary healthcare and work experience in resource limited settings.

\section{Undergraduate training}

Orientation of undergraduates to primary healthcare is done through training in community medicine at UHTC/RHTC. Community physicians are involved in field-based training of undergraduates. Community-based teaching which is practice-based, not theorybased is the need of the hour. ${ }^{[9]}$

\section{Training of public health (medical and paramedical) manpower}

Community physicians are involved in training (initiation and reorientation) of public health manpower working at various levels of healthcare.

\section{Technical expert}

A community physician provides technical expertise to plan, implement, monitor, and evaluate health programs. S/ he may also be a part of expert groups or committees in various health programs. $\mathrm{S} /$ he also provides technical expertise during outbreaks/epidemics.

\section{Research}

Community-based preventive, promotive, and curative interventions are tested at RHTC/UHTC. New programs or strategies are pilot tested before launching them on large scale. A community physician plays an important role in linking research to policy and program. ${ }^{[10]}$

\section{WHERE HAVE WE GONE WRONG?}

\section{Losing focus}

We have not taken the primary role of a community physician seriously. Many authors have focused upon provision of public health education: Undergraduate and postgraduate, our role as program managers and of course as researchers. They have not mentioned the primary role of a community physician. ${ }^{[5,11,12]}$ Provision of healthcare services should be an integral part of community medicine practice as this helps in developing a rapport and getting accepted by the community. ${ }^{[4]}$ It is the curative role that sets us apart from others and builds trust in the community. By not fulfilling our primary role we are trying to influence public policy without authority. ${ }^{[13]}$ There is a mention of posting PGs of community medicine in other clinical departments. ${ }^{[12]}$ This again is ironical given that the primary role of a community physician is to practice family medicine and a faculty of community medicine is the best option to train his PGs in the same.

There is a perception among us, our peers from other specialty and administrators that faculty of community medicine are involved only in teaching. For variety of reasons, despite being a clinical specialty, most of the departments of community medicine have restricted themselves to teaching undergraduates. They have comfortably ignored their other roles. They do not play a proactive role in developing working relationships with the healthcare delivery system ${ }^{[11-14]}$ and they lose the opportunity of learning from/contributing to the existing national health programs. Even if a health center is attached to the department, the faculty and postgraduates do not take active role in managing the center. The center tends to function like any other PHC; and hence, does not serve the purpose of being under the supervision of a Department of Community Medicine. In the absence of a health center under the department, community oriented teaching of Bachelor of Medicine, Bachelor of Surgery (MBBS) is conducted in PHCs over 
which the department has no administrative control. Centers and the service areas are merely used for teaching and training with no service provision. The so called RHTC/UHTC remain ornamental; to fulfill the norms of Medical Council of India (MCI). ${ }^{[12]}$

How many pediatricians would agree to work in a hospital under a medical college without a Pediatric Intensive Care Unit (PICU)? How many obstetricians would agree to work in a setup without a labor room? Why, then, do we agree to work in a set up without RHTC/UHTC, where one cannot practice what one learns? The administration also considers the department to be a teaching department and the department development is low on the priority list.

\section{Lacunae in postgraduate training in community medicine}

There is a lot of variation in training curriculum for community medicine PGs across India. MCI has given only broad guidelines and no standard curriculum is in place. ${ }^{[1]}$ Few institutes in India have an official curriculum for PG training. They, for practical purposes, are reduced to tutors who would handle undergraduate teaching and interns' training. ${ }^{[12]}$ They spend most of their time in the medical college and hospital. ${ }^{[1]}$ Academics, if any, remains delinked from field work in public health. It is unrealistic to expect to fulfill training needs of a community medicine PG unless the institutions and the department of community medicine in particular practice community medicine through their health centers and hospitals. ${ }^{[13]}$

\section{Attitude of faculty}

The faculty is disillusioned and pessimistic ${ }^{[11,14]}$ mainly because of the training they had received as PGs. Hence, their progenies are no different. This is further compounded by the fact that the specialty is not a popular choice among aspiring PGs. ${ }^{[1]}$

\section{Lost originality}

Another drawback is that academicians in India, like other specialists, have blindly tried to ape the west with regard to public health, as is commonly seen with other disciplines also. Be it change in terminologies or need for additional degrees in public health, we have knee jerk reactions and not planned, futuristic reforms. The evolution of the terms and specialties in UK had coincided with changes in the health administration and development in society; but in India, only the terminologies have changed and that too, out of context ${ }^{[15]}$ mostly as a consequence to the terminology changes in Western countries.

Sadly, no one has tried to understand why community medicine specialists, not a minority anymore, have failed to produce the desired result? Why was this cadre of specialists trained in first place in India? It was created to prepare social/community physicians. ${ }^{[7]}$ Instead of addressing this systemic problem, we are running a rat race in opening up other public health courses. As discussed before community medicine has clinical and nonclinical subspecialties. The nonclinical ones are the public health specialties which the government has hastily approved of. ${ }^{[7]}$ Clinical subspecialties are taking a back seat. The process of preparing community physicians is also taking a back seat.

\section{Models in India}

There are model initiatives in India borne out of a deeper understanding of the true purpose of this discipline and those trained in it. Few states in India have enacted the public health act where community medicine experts are directly involved in public health with a separate directorate for public health. ${ }^{[16]}$ Due to shortage of public health professionals or lack of appropriate decision making positions for public health professionals, personnel trained in providing hospital-based clinical services are often deployed to manage public health services. ${ }^{[17]}$ Policy decisions are generally taken by health secretaries of Indian Administrative Service (IAS) cadre and health ministers. They are advised by Director General Health Services and nodal officers of respective programs of district/state who are from nonpublic health background.

\section{WAY FORWARD FOR COMMUNITY MEDICINE: BACK TO THE BASICS}

Every community physician, especially in medical colleges, should perform his/her primary role of delivering healthcare services, irrespective of seniority and his subspecialty of interest. Besides this, RHTC and UHTC should be under complete administrative control of community medicine departments. Working in a setup with authority and accountability will ensure sustainability in the long run. By practicing community medicine, not just teaching, more problems will be identified; ideas would be generated to find a solution. ${ }^{[5]}$ In institutions like All India Institute of Medical Sciences (AIIMS), New Delhi, all national programs are implemented through the health centers of the department with PG or senior resident as the medical officer in charge..$^{[4]}$

Separate posts should be created for community physicians (like other specialties) at $\mathrm{CHC}$ level and above. Provision for preferential promotions or a separate promotion policy may be made. Further, to be able to perform their other roles, consultation groups of community physicians should be there at district level to guide bureaucrats and politicians in decision making. Enactment of public health act ${ }^{[16]}$ would be a step in this direction.

A behavioral and attitude change is required among existing practitioners of the discipline. Besides scientific publications and research projects, MCI may also lay down recommendations for appraisals and promotions of faculty of community medicine to consider their role in delivery of healthcare services in their UHTCs/RHTCs.

Radical changes have been suggested by some in this regard. ${ }^{[18]}$ Many suggestions have been made with respect to training of postgraduates $;^{[11,12]}$ they may be incorporated, with the holistic 
training as a community physician forming the core of the curriculum.

Some authors have expressed their view that community medicine be entirely scrapped and a new cadre of family physicians is prepared as has happened in UK; and core public health should be left to the public health specialists. ${ }^{[19]}$ Former group is entirely medical, whereas the latter may be a mix of medical and nonmedical. Despite pressure groups doing their best, the need to open separate MD course in family medicine without considering the existing trained health manpower and healthcare delivery of our country, appears totally unwarranted. In the end, this separate cadre of clinicians is going to perform the same role as a community physician; a large pool of which is already available in the country. It would also strain the finances of an already resource constrained health sector.

We are not suggesting that community physicians be deprived of options to specialize. They may indeed work in the subspecialty of their choice post residency. Other option is to offer sabbaticals ${ }^{[5]}$ to existing community medicine faculty to specialize in the superspecialty of their choice or based on the requirement of the healthcare delivery system. This way, we would be optimally utilizing the investment done in creating a large cadre of community physicians. Additionally, non-medicos may also be trained in public health through MPH, DPH, etc., to fulfill the need of the healthcare delivery system. This may pose a challenge to the current faculty of community medicine who are of clinical/ medical background. Some have suggested an all India public health cadre on the lines of IAS/Indian Police Service (IPS)/ Indian Forest Service (IFS). ${ }^{[17]}$

\section{CONCLUSION}

There is no denying that there are faculties of departments of community medicine who are fulfilling the primary professional role of a community physician. Agreed that our specialty is relatively young compared to other clinical specialties, agreed that appropriate job opportunities are few in the healthcare delivery system, but that does not justify the casual attitude with which our fraternity is happy performing the role of a teacher only. It is time we get back to the drawing board and perform the primary role of community physician; rest will follow.

\section{REFERENCES}

1. Kark JD, Abramson JH. Sidney Kark's contributions to epidemiology and community medicine. Int J Epidemiol 2003;32:882-4.

2. Warren MD. The creation of the Faculty of Community Medicine (now the Faculty of Public Health Medicine) of the Royal Colleges of Physicians of the United Kingdom. J Public Health Med 1997;19:93-105.

3. Bhore Committee [Internet]. 1946. Available from: http://www.nihfw.org/ NDC/DocumentationServices/Committe_and_commission.html [Last cited on 2013 Feb 12].

4. Nongkynih B, Anand K, Kusuma YS, Rai SK, Misra P, Goswami K. Linking undergraduate medical education to primary health care. Indian $J$ Public Health 2008;52:28-32.

5. Negandhi H, Sharma K, Zodpey SP. How can departments of community medicine shape the future of public health education in India? Indian J Public Health 2010;54:184-9.

6. Kumar R. Development of community medicine sub-specialities. Indian J Commu Med 2005;30:43.

7. Patro BK, Singh A. Community medicine departments and public health education in India at crossroads! Indian J Public Health 2011;55:56-7.

8. Kumar R. Academic community medicine in 21 st century: Challenges and opportunities. Indian J Community Med 2009;34:1-2.

9. WHO regional office for South East Asia. Improving the teaching of public health at undergraduate level in medical schools - suggested guidelines: Report of a review meeting of the expert group. Kathmandu, Nepal [Internet]. 2010 Aug 10-12. Available from http://203.90.70.117/ PDS_DOCS/B4674.pdf [Last cited on 2013 Feb 12].

10. Pandav CS. Role of faculty of medical colleges in national health policy and program development. Indian J Community Med 2010;35:3-6.

11. Lal S. Scenario of postgraduate medical education in community medicine in India. Indian J Community Med 2004;19:56-61.

12. Garg R, Gupta S. Are we really producing public health experts in India? Need for a paradigm shift in Postgraduate Teaching in Community Medicine. Indian J Community Med 2011;36:93-7.

13. Suresh K. Influencing public health without authority. Indian J Public Health 2012;56:22-30.

14. Mathur SC. Strengthening preventive and social medicine department in the medical colleges of Rajasthan. Indian J Community Med 2007;1:10-1.

15. Singh AJ. What is (There) in a Name. Indian $\mathrm{J}$ Community Med 2004;19:151-4.

16. Gupta MD, Desikachari BR, Shukla R, Somanathan TV, Padmanaban P, Datta KK. How might India's public health systems be strengthened? Lessons from Tamil Nadu. Econ Polit Weekly 2010;45:46-60.

17. Dasgupta S, Biswas K. Uniform all India public health cadre-need of the day. Indian J Public Health 2009;53:207-8.

18. Sai TS, Majumdar KK. Radical changes in public health-need of the hour. Indian J Public Health 2010;54:81-3.

19. Azhar GS, Jilani AZ. Future of community medicine in India. Indian $\mathrm{J}$ Community Med 2009;34:266-7.

How to cite this article: Shewade HD, Jeyashree K, Chinnakali P. Reviving community medicine in India: The need to perform our primary role. Int J Med Public Health 2014;4:29-32.

Source of Support: Nil, Conflict of Interest: None declared. 